\title{
Phycomyces and the biology of light and color
}

\author{
Enrique Cerdá-Olmedo * \\ Departamento de Genética, Facultad de Biología, Universidad de Sevilla, E-41012 Sevilla, Spain
}

Received 16 May 2001; accepted 2 June 2001

First published online 25 June 2001

\begin{abstract}
Phycomyces has been in the laboratories for about 140 years, sometimes following trends and fashions, but often anticipating them. Researchers have been attracted by the sensitive and precise responses of Phycomyces to light and other stimuli, coupled with easy manipulations and good adaptation to laboratory life. It is a simple prototype of the many organisms that use light as a source of information but not as a significant source of energy. Growth, development, genetics, and carotene production have been other subjects of pioneering research. Phycomyces was the second organism, after us, known to require a vitamin. It was one of the first organisms in the research on spontaneous mutants and the second, after Drosophila, in which mutations were induced artificially. It was used to coin the concept and the name of heterokaryosis. Phycomyces heterokaryons offer unique experimental possibilities, for instance in the study of gene function in vivo and the causes of cell death. An overall impression of parsimony and combinatorial gene usage arises from the genetic analysis of the complex functions of this fungus. The main subjects of recent attention have been the various reactions to light, gravitropism, and some aspects of metabolism, particularly the production of carotene. Interest in Phycomyces is slacking because of the repeated failures at transforming it stably with exogenous DNA. (C) 2001 Federation of European Microbiological Societies. Published by Elsevier Science B.V. All rights reserved.
\end{abstract}

Keywords: Photobiology; Sensory transduction; Behavourial genetics; Phycomyces blakesleeanus

\section{Contents}

1. From humid forests to the laboratory $\ldots \ldots \ldots \ldots \ldots \ldots \ldots \ldots \ldots \ldots \ldots \ldots$

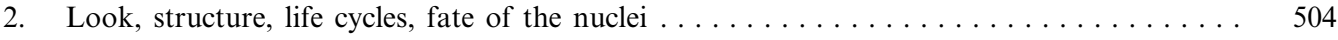

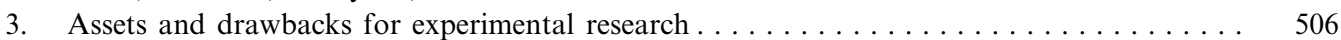

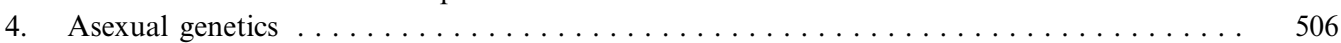

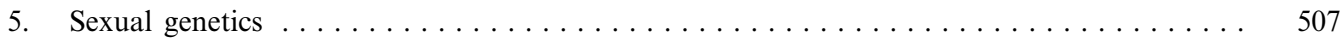

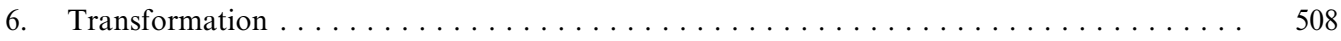

7. Sensory responses $\ldots \ldots \ldots \ldots \ldots \ldots \ldots \ldots \ldots \ldots \ldots \ldots \ldots$

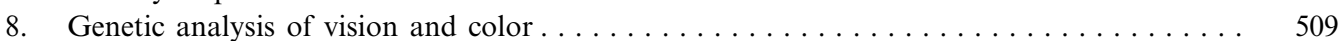

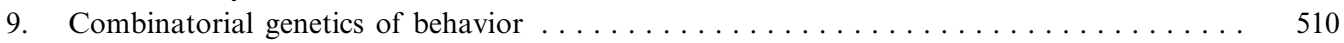

10. Carotene production and other practical applications $\ldots \ldots \ldots \ldots \ldots \ldots \ldots \ldots \ldots \ldots \ldots$

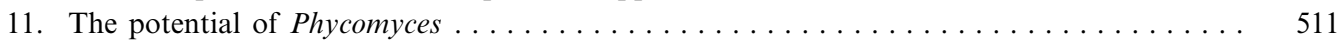

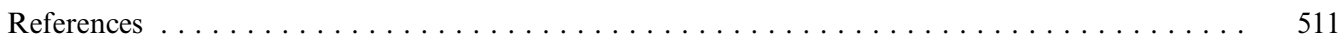

\section{From humid forests to the laboratory}

Phycomyces is a filamentous fungus present as a saprophyte in humid environments worldwide. Rarely seen in

* Corresponding author. Fax: +34 95462107.

E-mail address: eco@cice.es (E. Cerdá-Olmedo). nature, its spores are present occasionally in dung from mammals collected in humid forests. It was reported for the first time in Sweden in 1817 as a green alga and called Ulva nitens. The bizarre confusion inspired the genus name, Phycomyces, 'algal fungus', assigned to it in 1823. In 1925, on the basis of scant evidence, the original species, Phycomyces nitens, was split in two, and the most common laboratory strains were assigned to the new Phy- 
comyces blakesleeanus. Recent sequence comparisons support the distinction and the recognition of a family, Phycomycetaceae, separate from the Mucoraceae (the taxonomic home of Mucor and Rhizopus) and the other families in the order Mucorales. As a member of the class Zygomycetes, Phycomyces is about as distant from the Ascomycetes, the plants, and the animals as these groups are from each other.

Phycomyces was brought to laboratories because of the size of its vegetative fruiting bodies, the macrophores, and kept because of its easy cultivation. Jean-Baptiste Carnoy, a Belgian priest who wanted to uplift science at the Université de Louvain, then lagging behind its rival Université Libre de Bruxelles, was sent to Rome for training. He found Phycomyces growing on human feces in a cave and took it as an experimental subject. His main publication [1] contains a good description of the growth, development, and behavior of what he called Mucor romanus, but also the astonishing discovery of its gradual conversion into all sorts of fungi as it was allowed to grow on different substrates. For this work he received the royal prize for science and the derision of other scientists.

The effects of light on Phycomyces were described in the early days of microbial physiology [1-3] and have remained an active subject ever since. The pace quickened when Max Delbrück left phage in search of a new frontier and took up Phycomyces to find the biological basis of behavior in the 1950s. The most puzzling response of Phycomyces macrophores, 'avoidance', or growth away from practically any object close to their growing zone, was an early observation [4] that has not yet been satisfactorily explained. Phycomyces was used by Alfred F. Blakeslee [5] to discover the sexual reproduction of the Mucorales. The recognition of sensory responses and sex changed our perception of the fungi, which had long been considered 'vain superfluous humidity of the soil' [6].

The genetics of Phycomyces were initiated by Blakeslee [7] and benefited from the prolonged dedication of Hans Burgeff $[8,9]$, who coined the concept and the term heterokaryon, but failed in his attempt to understand meiosis. Genetics became a tool in photobiology in 1967, when the first behavioral mutants were isolated in Delbrück's laboratory, and led soon to the first chart of the sensory transduction pathways [10], which describes the flow of information from the sensors to the effectors.

Biochemical research on the yellow pigmentation of Phycomyces was started by T.H. Goodwin more than 50 years ago. Major contributions have been made to the description of the biosynthetic pathway for $\beta$-carotene. The regulation of carotene content, which is particularly complex in Phycomyces, is understood better in this organism than in any other.

Phycomyces research was summarized and examined critically in a book [11], which contains an exhaustive literature list and descriptions of techniques peculiar to this organism. There are specialized reviews on the major

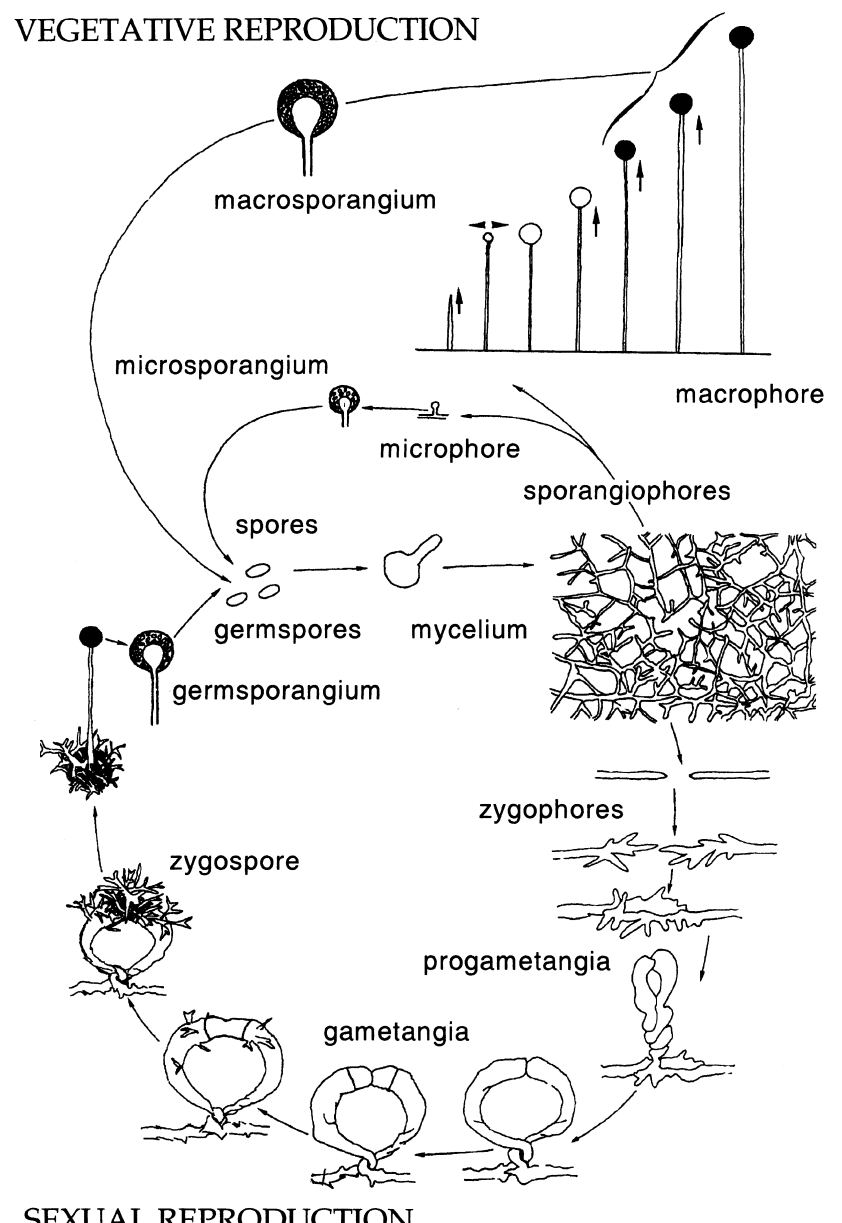

SEXUAL REPRODUCTION

Fig. 1. The life cycles of Phycomyces. Dormant spores, activated and incubated under suitable conditions, germinate to produce a mycelium, which is a branched cell of indefinite extension. Out of the mycelium grow two kinds of sporangiophores: macrophores and microphores. The stages of macrophore development are characterized by their growth (apical, radial, absent, intercalar) and the development of the sporangium; the growing zone of adult macrophores is a small cylindrical section below the sporangium. Sporangia contain spores, which complete the asexual cycle. Sexual reproduction starts when mycelia of opposite mating type grow near each other; both develop thicker hyphae, called zygophores, in response to chemical signals from the other. Progametangia are the zygophores of opposite mating type that come in contact, twist around each other, and finally adopt the shape of tongs. Gametangia are the two cells, separated at the ends of the progametangia, that fuse to form the zygospore. The zygospore is decorated with appendages, blackens, thickens, and rests for months. Germination of the zygospore gives rise to a germsporangiophore, a germsporangium, and germspores, all very similar, in terms of morphology and physiology, to their vegetative counterparts.

effects of light: phototropism [12-15], photomorphogenesis [16] and photocarotenogenesis [17]. The reader is directed to these sources and the references therein to support and extend the assertions made here.

\section{Look, structure, life cycles, fate of the nuclei}

The Phycomyces life style offers both assets and draw- 


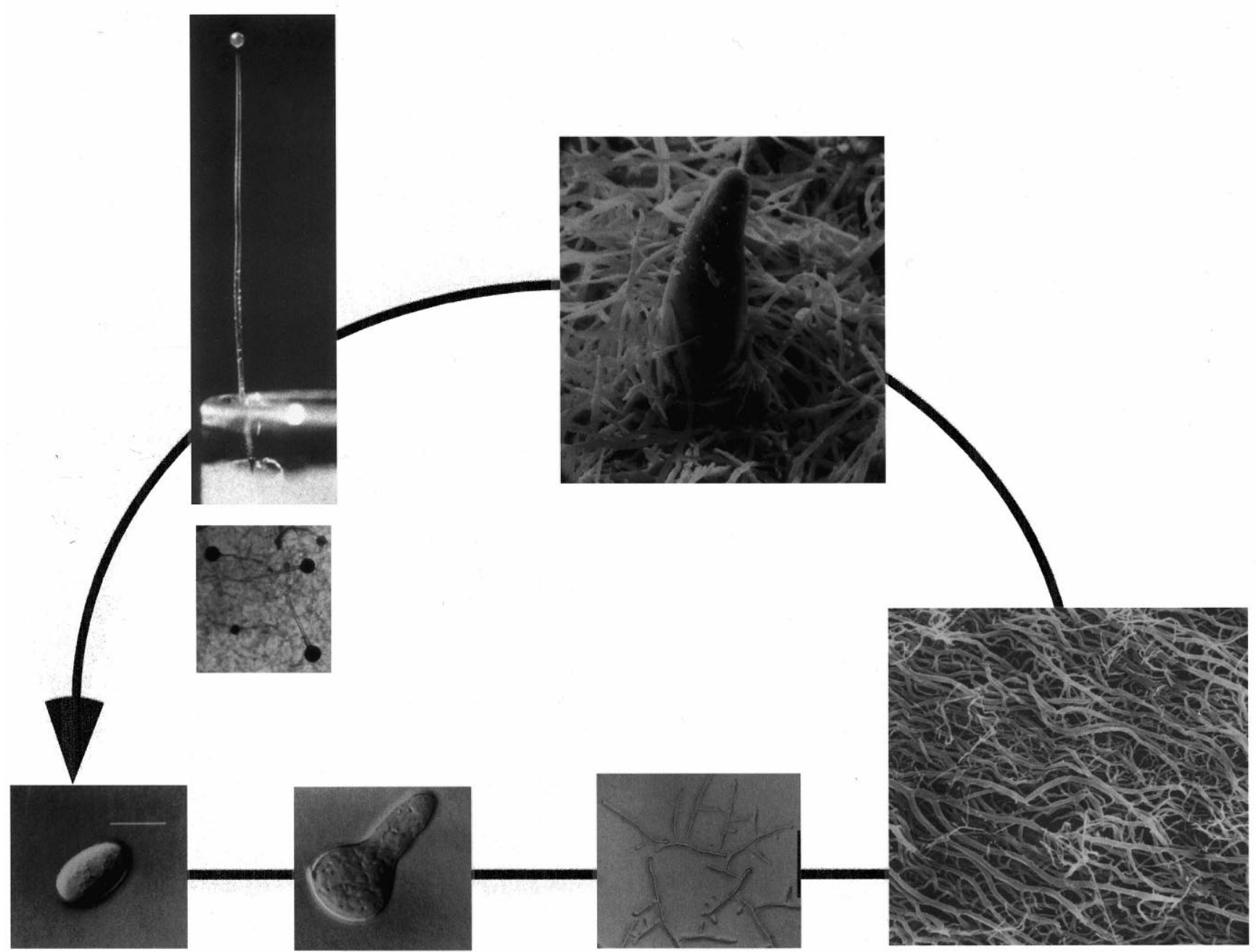

Fig. 2. Structures of the vegetative cycle. The spores are about $9 \mu \mathrm{m}$ long. Their germination produces one to three germinating tubes that grow into a branched mycelium; most mycelial hyphae are about $10-20 \mu \mathrm{m}$ in diameter. Macrophores and microphores grow out of the mycelium into the air. Macrophores (above left) become several $\mathrm{cm}$ long; their sporangia, some $0.5 \mathrm{~mm}$ across, contain about $10^{5}$ spores. Microphores (shown under the macrophores) are about $1-3 \mathrm{~mm}$ long; their sporangia, some $0.1 \mathrm{~mm}$ across, contain about $10^{3}$ spores.

backs for the researcher. The various stages (Figs. 1 and 2) differ in morphology, biochemistry, physiology, and behavior. The mycelium is composed of cylindrical, branched hyphae which grow on surface cultures and in shaken or aerated liquid media. Under quiet culture conditions, the mycelium produces fruiting bodies, the sporangiophores, that grow into the air and develop an apical sporangium filled with spores. There are two main kinds of fruiting bodies, called macrophores and microphores, which differ in size, development and behavior. The spores disperse efficiently when they adhere to passing animals or are eaten by them.

Not only the spores, but nearly all other stages grow to form mycelia when provided with suitable conditions. Old mycelia, even months after sporulation, contain small masses of cytoplasm with a few nuclei, the propagula, ready to resume growth if conditions allow. In contrast to other fungi, the hyphae do not fuse with each other spontaneously; i.e. there is no anastomosis. Mycelial pieces do not always provide pure cultures because they may consist of intertwined hyphae of different individuals. Plucked macrophores grow for many hours and develop normally when provided with water at their base. When submerged in culture medium, they produce mycelia; laying a young macrophore in fresh agar is a good way to purify a single mycelium from a mixture.

Phycomyces departs from most laboratory organisms in being coenocytic (Fig. 3). Mycelia, macrophores, microphores, and young sporangia form a cytoplasmic continuum inhabited by many nuclei, traversed by strong currents, and not interrupted by septa or cell walls. Spores are multinucleated, except for the few that are uninucleated.

The sexual cycle of Phycomyces starts when mycelia of the two mating types, often called sexes, meet on a solid surface. The most apparent result is the formation of zygospores, large cells with thousands of nuclei of both parents. Zygospores rest for at least 2 months and then ger- 


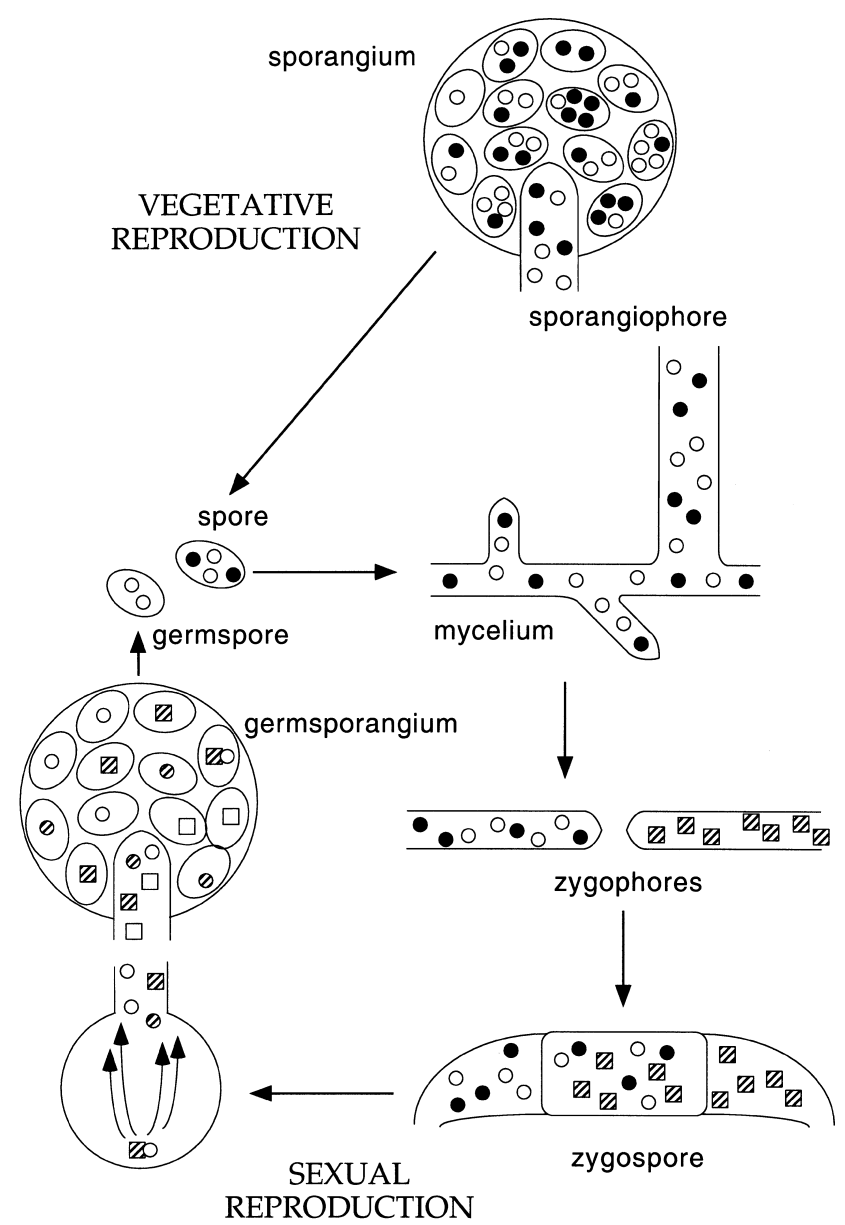

Fig. 3. Karyology of the life cycles. Phycomyces is nearly always a coenocytic organism. Vegetative spores encase random samples of nuclei from the young sporangium; only a tiny proportion of the spores are uninucleated $(0.3 \%$ in the standard wild-type). The nuclei may not be genetically identical; the vegetative reproduction of a heterokaryon with two kinds of nuclei will form heterokaryotic spores with both kinds of nuclei and homokaryotic spores with either kind. In the sexual cycle, the zygospore contains thousands of nuclei of both mating types, but in most zygospores a single diploid gives rise to all the progeny. The nuclei in the germspores are the products of recombination of the parental markers. Circles and squares represent the two mating types; open, closed, and hatched symbols, different genetic markers.

minate in relative synchrony, that is, within about 1 month, without the need to be fed anything but water. Each zygospore produces a macrophore, which is very similar to those of the asexual cycle, and develops a germsporangium with germspores. Germspores are multinucleated, but, unlike vegetative spores, derive from uninucleated primordia.

\section{Assets and drawbacks for experimental research}

Phycomyces grows vigorously at room temperature using many common sources of carbon and nitrogen. Mycelia expand indefinitely, but they form distinct colonies if the medium is acidic or contains detergents. When composing the first chemically defined media, Burgeff noticed that, depending on the supplier, maltose could serve as the only carbon source. He showed that maltose worked only if contaminated with thiamine, and this led to the recognition of Phycomyces as vitamin dependent, a natural auxotroph. Phycomyces growth provided a simple quantitative assay for thiamine in complex organic materials, which was a standard analytical tool for many years.

The macrophores, subject of much behavioral research, are giant cylinders, several $\mathrm{cm}$ or $\mathrm{dm}$ long and about 0.1 $\mathrm{mm}$ wide. Growth, perception, and response to stimuli occur just below the sporangium or at the tip, before the appearance of the sporangium. The size of the macrophores facilitates the measurement of the velocity and direction of growth. Computer-steered devices help program the stimuli, measure the responses and analyze their relationship. The relatively simple cylindrical structure has led to detailed calculations and measurements of the distribution of stimuli such as light [18].

The size and the sturdiness of the macrophores have made it possible to adapt techniques from material science and mechanical engineering to measure the water relations and the mechanical properties of cell walls in vivo. The results reveal the roles of turgor pressure and cell wall loosening and synthesis in growth [19]. Additional experimental possibilities are offered by the aptitude of macrophores for regeneration and by the relative ease of injection of chemicals and viable organelles into living macrophores [20].

\section{Asexual genetics}

The multinucleate nature of Phycomyces hinders genetic analyses, but opens the way for some special techniques that cannot be matched in any other organism.

The rare uninucleated spores can be separated from multinucleated ones by a cumbersome mechanical procedure, but there is a simple genetic method to select colonies derived from uninucleated spores. The riboflavin analogue, 5-carbon-5-deazariboflavin, harmless to most organisms, is extremely toxic to Phycomyces. Resistance is due to the loss of riboflavin permease by mutations that are very recessive and therefore expressed in uninucleated spores only, but are sufficiently frequent that about two spores in a million are spontaneously resistant. The nuclei in a mycelium can be sampled by plating its spores on minimal agar containing the inhibitor [21].

Recessive mutants that can be selected are isolated readily after treating spores with mutagens that kill nuclei, so that many of the survivors become functionally uninucleated. When the desired mutants cannot be selected, but must be screened individually, the multinucleated survivors constitute an unproductive workload. This nuisance can be avoided by a genetic trick [22]. The mutagen is applied to the spores of a heterokaryon in which a minor- 
ity of the nuclei carry a selectable recessive marker; the survivors are first selected for the marker and then screened for new recessive mutations.

Coenocytes can be heterokaryotic because their many nuclei need not be all genetically identical. Heterokaryons arise by spontaneous mutation and by segregation of diploid germspores and can be obtained by several manipulations, particularly by grafting macrophores from different strains. Heterokaryosis can be maintained in successive vegetative generations because the nuclei in the multinucleated spores are random samples from the nuclei in the mycelium. Thus, $\operatorname{car} R$ and $\operatorname{car} B$ mutants are red and white, respectively, owing to the loss of different enzymes needed to produce $\beta$-carotene; heterokaryons of $\operatorname{car} R$ and $\operatorname{car} B$ mutants are more or less yellow and similar to the wild-type because they contain both enzymes and accumulate a mixture of pathway precursors and the final product, $\beta$-carotene. Recessive mutations can be assigned to genes by complementation tests in Phycomyces heterokaryons, much as it is done in other organisms.

It is possible to obtain heterokaryons with any proportion of the constituent nuclei and to calculate such proportions, or nuclear ratios, from the frequencies of phenotypes among the colonies grown from the spores of the heterokaryon. Nuclear ratios are maintained during mycelial expansion, sporangiophore development, and successive subcultures through pieces of young mycelia [23]. These exclusive features of Phycomyces heterokaryons are the basis of unique and powerful methods.

The isolation of mutants from heterokaryons offers direct information on their dominance or recessivity. Thus, recessive mutants isolated from the spores of heterokaryons of $\operatorname{car} R$ and $\operatorname{car} B$ mutants must be either red or white; yellow mutants isolated in this way contain dominant mutations (except for some rare revertants and suppressors). The proportion of dominant and recessive mutations can be estimated from the nuclear proportion in the original heterokaryon and the color distribution in the mutants.

Dominance and recessivity are not qualitative, but quantitative concepts. Precise phenotypic measurements can distinguish the heterokaryons with wild-type and mutant alleles from the respective homokaryons and complementing heterokaryons from the wild-type. Phenotypic measurements of heterokaryons can be expressed as a function of the proportion of their nuclei that carry a certain allele. Such functions may give considerable information on the action of the corresponding gene products. For example, the structure and operation of the enzyme aggregate for carotene biosynthesis were established from carotene analyses of heterokaryons of car mutants [24].

Phycomyces heterokaryons can elucidate the causes of cell death after exposure to any lethal agent. This is done by determining the frequency of heterokaryons among the survivors of lethal treatments. The test provides quantitative estimates of the relative contribution of four major classes of lethal events and prevents the frequent error of regarding as causes of cell death events that are only its consequences [25].

\section{Sexual genetics}

New genetic combinations arise during the sexual reproduction of two strains of opposite sex, a slow process because of the long dormancy of the zygospores. Germination of a zygospore produces a single germsporangium with anything from a few to tens of thousands of germspores, each able to give rise to a mycelial colony, usually homokaryotic and haploid.

The colonies obtained from germspores pooled from many germsporangia represent all the haploid combinations expected from a cross and permit standard genetic analyses, similar to those carried out with most plants and animals. Recombination is so active that recombinants for markers within a gene may be detected by analyzing a few hundred pooled germspores. Only about 3\% of randomly chosen genetic markers are linked; they had been ordered in a genetic map with 11 linkage groups [26]; the actual number of chromosomes is unknown.

When single germsporangia are considered, the number of germspores, the presence of different genotypes, and their frequencies are extremely erratic and puzzling. By crossing heterokaryons with appropriate markers, the nuclei in most germsporangia were shown to derive from a single diploid nucleus, formed by a haploid nucleus from each parent [27]. The many nuclei in young zygospores disappear within a few days, coinciding with a burst of nucleases and other hydrolases. Nuclei are seen again after germination of the zygospore. Presumably, most nuclei in the zygospore are degraded and their materials used to allow the founding pair to produce all the nuclei in the germspores.

The early and durable conjecture that germspores represent the products of a single meiosis in the zygospore has been rejected by the study of multiply marked crosses [21]. A single meiosis would produce four meiotic products, but more than four different genotypes are found regularly in each germsporangium. Genetic analyses and searches for synaptonemal complexes have failed to provide evidence for meiosis.

In the first study of sex in the fungi, about a century ago, Alfred Blakeslee observed that a small proportion of Phycomyces germspores grow into colonies with a distinct appearance and bizarre sexual behavior. They have been shown recently to carry diploid or partially diploid nuclei heterozygous for the sex markers and to grow into mycelia that contain complex mixtures of haploid and partially diploid nuclei [21]. This is evidence for a process of haploidization that does not involve meiosis, but repeated cycles of recombination and random chromosome loss, much as it occurs in the parasexual cycle. 


\section{Transformation}

More than 20 years of work at several laboratories in three parts of the world have been wasted on attempts to transform Phycomyces with DNA. Protoplasts have been transformed at low frequencies with replicative plasmids, but these are modified and destroyed in the cell, resulting in loss of the transformed phenotype. The aggression does not seem to be limited to the introduced DNA, because very high lethality and mutation rates have been detected in Phycomyces nuclei after the injection of DNA into cut sporangiophores. These results represent the greatest frustration in the laboratory career of Phycomyces and is a serious impediment to the molecular genetics of the behavior and the biochemistry of this organism. A related fungus, Mucor circinelloides, can be transformed with replicative plasmids [28] and the rare integration events can be used for gene disruption. The lack of giant macrophores and of a sexual cycle limits the attractiveness of this Mucor as a research subject.

\section{Sensory responses}

Phycomyces responds in various ways to many external stimuli: except for being deaf, it possesses all the senses traditionally recognized to humans. Most parts of the fungus respond to light in one way or another. In the mycelium blue light stimulates the development of macrophores and the accumulation of $\beta$-carotene and inhibits the development of microphores. The most conspicuous response of macrophores to blue light, but not the only one, is their tropism, or growth towards the light source. Other stimuli that modify macrophore growth include red and green light, ultraviolet and ionizing radiations, gravity, wind, odors, and pressure. Hyphal tips slow their growth when they approach hyphae of Phycomyces and other Mucorales, but not of other fungi. Sexual interactions begin with an exchange of chemical signals between the mycelia of opposite sex that increase the carotene content and modify the morphology and the behavior of hyphal tips. The most mysterious sensory response of Phycomyces is avoidance, that is, the growth of the macrophores away from just about any object, including threads and liquids, that happen to be near their growing zone.

A copious literature describes phototropism and other responses that lend themselves to precise measurements. The response intervals are impressive; thus, the lower threshold for phototropism is about $1 \mathrm{nW} \mathrm{m}^{-2}$, or about the fluence that we receive from a single star; to dazzle Phycomyces requires about $10^{10}$ times more light, that is, direct exposure to the sun on a bright day. Two photosystems, optimized for different light intensities, are used to master such a wide range; each elicits two responses, an immediate one, starting within a few minutes, and a delayed one. It is not surprising that the response at a given moment is a complex function of the past illumination program.

The mycelial responses called photomacrophorogenesis, photomicrophorogenesis, and photocarotenogenesis also have extended response intervals and depend on two photosystems each. The eight photosystems share overall similarities, but differ significantly from each other in their quantitative parameters, including action spectra.

The sensitive zone of the macrophore coincides roughly with the growing zone, a transparent cylinder about 0.1 $\mathrm{mm}$ in diameter and about $3 \mathrm{~mm}$ long. Stimuli applied asymmetrically to the growing zone of the macrophore change the direction of growth. Blue light, near ultraviolet radiation, wind, and pressure provoke positive tropism, i.e. growth towards the source of the stimulus. Ultraviolet radiation below $310 \mathrm{~nm}$ in wavelength, gravity, and obstacles induce negative tropisms. Stimuli applied symmetrically around the macrophore axis cause slight transient changes in growth velocity (mecisms).

Refraction of incoming light at the cell wall produces strong focusing bands on the opposite side of the cell; except in special cases, other refractions, reflections, scattering, and absorption play minor roles in the optics of the growing zone. The photoreceptors are located at the plasma membrane, on the inner face of the cell wall around the growing zone. The response depends not only on the local illumination, but on the distribution of light around the cylinder [18]. The dichroism of the photoreceptors and their fixed orientation on the plasma membrane result in different responses to light according to its plane of polarization [29].

Macrophores react to changes in light intensity and direction and, in the absence of changes, adopt a standard growth velocity of about $1 \mu \mathrm{m} \mathrm{s}^{-1}$. After being brightly illuminated for some time, Phycomyces, like us, takes a long time to react to a dim light. The kinetics of adaptation of Phycomyces to the dark, like ours, are such that the dimming of day light in the afternoon remains unnoticed for long. The adaptation is influenced by extremely sensitive photoreceptors, which have a threshold of about $3 \mathrm{pW} \mathrm{m}^{-2}$ in the blue and respond to green and red light as well.

Macrophores, because of their size and their guidance by various stimuli, bring the spores out of the decaying organic matter that feeds the mycelium and facilitate their dispersal. Microphores may be seen as cheap alternatives made when the supplies are scarce or the chances for longrange dispersal are poor. The production of one or the other kind is determined by illumination, the composition of the local atmosphere, and other physiological and environmental circumstances.

The mycelial responses, photomorphogenesis and photocarotenogenesis, are common phenomena in fungi, plants and algae; Phycomyces is unique for its sensitivity. The photomorphogenetic threshold corresponds to a flow 


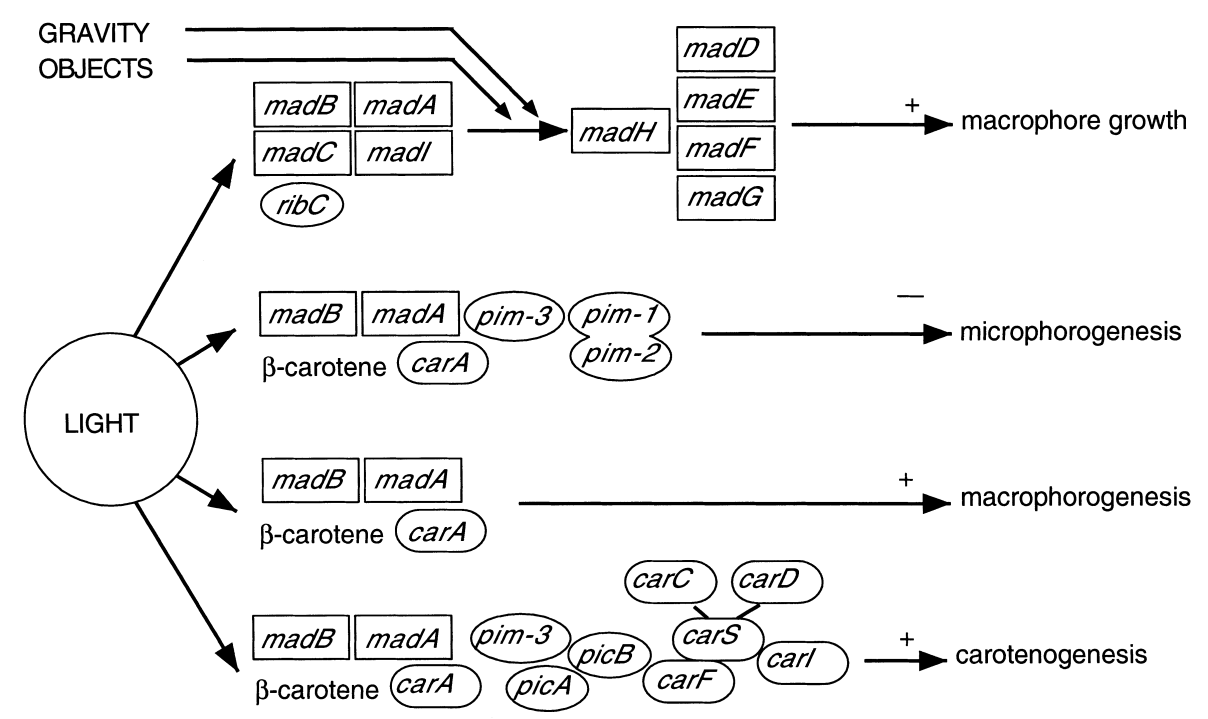

Fig. 4. The sensory pathways of Phycomyces link the stimuli (left) and the responses (right). The flow of information is hindered by mutations at the genes given in italics or by lack of $\beta$-carotene.

of one photon per $\mu \mathrm{m}^{2}$ of hyphal surface every $20 \mathrm{~min}$ and the threshold for photocarotenogenesis is even lower. Photosensitivity is not a constitutive trait, but a part of the developmental program. Photodetectors become active during a certain period of a few hours and the competence periods of the different mycelial responses do not coincide precisely.

\section{Genetic analysis of vision and color}

Various aspects of Phycomyces development and metabolism have been subjected to genetic analyses, but most of the efforts have been devoted to the photoresponses and the production of $\beta$-carotene. These two topics are connected because the production of $\beta$-carotene is one of the photoresponses and because many mutants of carotene biosynthesis exhibit complex phenotypes, including behavioral changes.

Sensory pathways represent the flow of information from sensors to effectors, directly or through additional sensory transducers. They are based on the phenotypes of behavioral mutants, which are often pleiotropic, and are formally similar to biochemical pathways. The genetic analysis of behavioral mutants may identify the elements that compose sensory pathways and establish their relationships. The current picture of the Phycomyces sensory pathways (Fig. 4) is still partial, because the isolation of new behavioral mutants is far from saturation and their analysis is not complete.

Some behavioral mutants exhibit gross morphological alterations. This is the case of the piloboloides mutants, first reported in 1912, which have bulging growing zones just below the sporangia. Observation of their negative phototropism confirms that Phycomyces does not respond to the direction of light, but to its distribution in the growing zone [30].

The riboflavin auxotrophs (rib genes) are nearly normal for phototropism, but this does not eliminate riboflavin and its derivatives as photoreceptors, because the amounts required for normal growth may be higher than those required for normal vision. Observations carried out with these and other mutants support the candidacies of riboflavin and a pterin for the role of main chromophores in phototropism [14]. A membrane protein that binds free riboflavin reversibly is a plausible photoreceptor apoprotein [31].

The biosynthesis of carotene from geranylgeranyl pyrophosphate requires eight chemical steps. In an example of genetic economy, the eight reactions are catalyzed by three enzymes, the products of just two genes, $\operatorname{car} B$ and $\operatorname{car} R A$, which are adjacent and divergently transcribed [32]. A complete lack of $\beta$-carotene (mutational inactivation of both genes) does not affect phototropism, but blocks photophorogenesis and photocarotenogenesis. Therefore, $\beta$ carotene cannot be a chromophore for phototropism, but plays a fundamental role in the other responses to light, probably as an antenna pigment.

The cellular concentration of $\beta$-carotene is determined by external factors, including blue light and many chemicals, and by the activity of several gene products. The regulation operates by setting the level of transcription of the structural genes and the activity of the first enzyme, the $\operatorname{car} A$ gene product. Mutants of genes $\operatorname{car} S$, $\operatorname{car} D$, and $\operatorname{car} F$ contain much more carotene than the wild-type and mutants of genes $\operatorname{carC}$ and carI contain less. The pigmentation of the growing zone has a relatively minor effect on phototropism. The absorption of light by carotene is one of the factors that influence the equilibrium between positive tropism to blue light and negative tropism away from 
ultraviolet radiation. The null wavelength that separates the opposite effects is $310 \mathrm{~nm}$ in the wild-type grown under standard conditions, but becomes longer or shorter when the $\beta$-carotene concentration of the growing zone is higher or lower, respectively.

The mad mutants are isolated because of defective phototropism; for example, they may not turn downwards or sidewards to a light source as the wildtype does. The mad mutants define 10 unlinked genes, singled out with the first 10 letters of the alphabet. There are many detailed descriptions of the behavior of the mad mutants in response to light and other stimuli, but comparatively few biochemical analyses. The mad mutants can be classified in two major classes, although most mad gene products seem to be associated physically with each other.

The essential change in mutants of genes $\operatorname{mad} A, \operatorname{madB}$, $\operatorname{mad} C$, and $\operatorname{madI}$ (the class 1 mutants) is that they trope towards a certain blue light source just as the wild-type would do towards a weaker one. The response to bright light sources disappears in the triple mutants $\operatorname{mad} A \operatorname{madB}$ $\operatorname{mad} C$, which are completely blind. The action spectra of $\operatorname{madB}, \operatorname{mad} C$, and $r i b C$ mutants seem to differ from that of the wild-type not only in the overall efficiency, but in the shape (relative wavelength dependence); these mutants seem to have lost different elements of a complex photoreceptor that contains several chromophores.

Mutants in other mad genes (the class 2 mutants) are defective in gravitropism and avoidance, as well as in phototropism; they react more quickly (gene $\mathrm{madH}$ ) or more slowly than the wild-type (genes $\operatorname{mad} D, \operatorname{madE}, \operatorname{mad} F$ and $\operatorname{mad} G$ ), sometimes so slowly that they appear completely unable to respond. There are reasons to believe that the corresponding gene products are involved in the regulation of growth of the cell wall in the growing zone. This implies a local weakening of the chitin fibers by chitinases, which results immediately in a passive longitudinal extension, and the subsequent reinforcement by new chitin synthesis.

The adaptation to darkness depends on the products of some $\mathrm{mad}$ genes. Thus, $\mathrm{madH}$ mutants adapt more rapidly than the wild-type; $\operatorname{madB}$ mutants do it more slowly and are defective in the modification of adaptation by light.

Ultraviolet radiation is absorbed by the chromophores that absorb blue light and require mad gene products for action, but this does not explain the opposite directions of blue and ultraviolet $\mathrm{C}$ tropisms. The strong ultraviolet $\mathrm{C}$ absorbency of gallic acid present in the macrophores is not an explanation, because a mutant that is almost devoid of this phenol turns away from ultraviolet sources [33]. The existence of gene products specific for the negative response is confirmed by the isolation of $u v i$ mutants that react normally to blue light, but defectively to ultraviolet $\mathrm{C}$ radiation.

Gravitropism is a slow response, because it takes hours, while phototropism and avoidance take minutes. Mutants with faster or slower gravitropism than the wild-type have been isolated. Some mutants with defective gravitropism lack certain protein crystals that probably act as statoliths [34].

The phenotypes of many mutants show that the tempo of each tropism results from an evolutionary choice. Responding more or less quickly to different stimuli presumably allows the cell to set priorities when it receives contradictory orders from different sensors.

Phototropism and the three mycelial photoresponses share a number of features, which suggest a common evolutionary origin, but they differ in their biochemical and genetical requirements. All depend on the $\operatorname{mad} A$ and $\operatorname{madB}$ gene products, all have similar, but not identical, action spectra, and each is the sum of two responses, geared to different light intensities. The mycelial photoresponses, but not phototropism, depend strictly on $\beta$-carotene and are partially defective in car $A$ mutants. The partial defects of the car $A$ mutants are not due to their meagre $\beta$-carotene supply, because the defects remain in double mutants car $A$ car $S$ which have more carotene than the wild-type. The pim mutants produce microphores under constant illumination that completely prevents their appearance in the wild-type; the detailed analysis of these mutants shows that macrophores and microphores are the products of two separate morphogenetic responses.

The induction of carotene biosynthesis by light is defective in many mutants. They include pic $A$ and picB mutants, which remain pale yellow when grown in the light. Defective photocarotenogenesis is found in $\operatorname{mad} B, \operatorname{mad} A$, $\operatorname{car} C$, car $S$, carI, and carA mutants, listed in the probable order of action of the gene products, according to epistasis and other indications. The carI and carA mutants of this group are defective, not only in photocarotenogenesis, but in the response to many chemicals that stimulate carotene biosynthesis in the wild-type. The first enzyme of the carotene pathway is their common regulatory target.

Activation of carotene biosynthesis is an early sexual response, brought about by a group of chemicals, the trisporoids, that are exchanged by mycelia of different sex. Trisporoids derive from $\beta$-carotene and, therefore, mutants that do not produce $\beta$-carotene fail to stimulate their partners and do not enter the sexual cycle. There have been no investigations on the reception or the transduction of the sexual signals, although defective mutants are easily obtained.

\section{Combinatorial genetics of behavior}

The sensory pathways in Fig. 4 summarize the preceding presentation and many additional details. The overall impression is that of an economical use of genetic resources, because it is a common finding that a gene product acts in several pathways. This may have been a consequence of a relatively quick and recent development of the sensory abilities of Phycomyces, which seem to be much richer than those of its taxonomic relatives, such 
as Pilobolus kleinii [35] and other Mucorales. A combinatorial use of gene functions is a parsimonious way to set up a complex behavior. Different blue light receptors share a common core that requires the $\operatorname{mad} A$ and $\operatorname{mad} B$ gene functions and combine with different effectors to carry out the various responses to light. Different stimuli, such as blue light, gravity, and obstacles, share the effectors that regulate macrophore growth. Several genes seem to be specific for a single response, but it is not excluded that further research will find multiple uses for their products.

\section{Carotene production and other practical applications}

Phycomyces is not known to produce toxins, although its chemical composition has been investigated in considerable detail. It is probably safe for mammals: the fact that the dung of small mammals is the best natural source for Phycomyces spores suggests a regular consumption as food. There is no record of pathogenicity for man, animals, or plants. Warm-blooded animals are naturally protected against Phycomyces by its maximum growth temperature of only $28^{\circ} \mathrm{C}$.

Phycomyces is a potential source for edible oil [36] and various chemicals [37], including $\gamma$-linolenic acid and $\beta$ carotene. The first is a vitamin that is abundant in fish oil, but is present in very few plants and could be deficient in vegetarian diets for man or animals. The second is an attractive food colorant with beneficial effects on health, due in part to its function as pro vitamin A.

Overproduction of $\beta$-carotene in Phycomyces may be viewed as a practical application of sensory physiology. The carotene content of the wild-type grown under standard conditions is modest (about $0.05 \mathrm{mg}$ per $\mathrm{g}$ dry mass, less than in commercial carrots). Blue light and certain chemicals increase that content, but the former would be impractical in industry and the latter would endanger the environment or the consumer. These stimulating agents are rendered superfluous by the use of certain genotypes, such as the $\operatorname{car} S$ carF double mutants, which do not respond to them and accumulate about $10 \mathrm{mg} \beta$-carotene per $\mathrm{g}$ dry mass under standard conditions.

The sexual stimulation of carotene biosynthesis remains essential to increase yields, up to $35 \mathrm{mg} \mathrm{g}^{-1}$ in appropriate strains. All the known carotene overproducing strains respond to sexual stimulation. Mixed cultures of strains of opposite sex are not ideal, because the unbalance of the strains reduces the stimulation, at least locally. Intersexual heterokaryons, which contain nuclei of opposite sex, are perfectly viable, but tend to segregate mycelial sectors with predominance of one or the other type of nuclei. Intersexual heterokaryons can be stabilized by the introduction of recessive lethal mutations in the constituent nuclei, but these mutations are not necessarily completely recessive and may cause some damage. The best way to exploit sexual stimulation is the use of strains that are diploid or at least disomic for chromosome I, which carries the sex determinants. Such strains occur naturally as infrequent segregants of genetic crosses [21].

Lycopene, the main pigment from red tomatoes, is increasingly attractive for industry and may be supplied by Phycomyces car $R$ mutants, which cannot carry out the cyclizations that convert lycopene to $\beta$-carotene. The various ways to overproduce $\beta$-carotene can be applied to lycopene with an additional precaution: the use of a leaky mutant, because sexual stimulation cannot be achieved in the complete absence of $\beta$-carotene.

The best strains of Phycomyces bear their full carotenogenic potential on solid substrates or in quiet liquid media. A relative, Blakeslea trispora, is more appropriate for production in the usual fermenters. Although these moulds do not share many aspects of the regulation of carotene biosynthesis, the progress made with Phycomyces has been used to guide strain improvement in Blakeslea.

\section{The potential of Phycomyces}

As we have seen, research with Phycomyces diverges in many ways from research with other organisms and has singular advantages and drawbacks. At the end of their careers, the two most famous investigators of Phycomyces, Hans Burgeff and Max Delbrück, were not completely enthusiastic about this organism. Burgeff [9], after recognizing the difficulties of genetical analysis in Phycomyces, concluded: 'I do not believe that this is a justification for giving up. We cannot eat just the soft parts of the cake of Science and leave the hard ones for our followers to gnaw'. Max Delbrück said: 'I am still convinced that Phycomyces is the most intelligent primitive eukaryote... I do not expect to make great discoveries, but if I continue to do the spade work my successors may do so' [38].

Many of the obstacles found by Burgeff and Delbrück in their work with Phycomyces have been removed, but a new one has appeared, the failure at stable transformation with exogenous DNA. Even if this obstacle was to remain, there are still many possibilities for pioneering work with this organism.

\section{References}

[1] Carnoy, J.B. (1870) Recherches anatomiques et physiologiques sur les champignons. Bull. Soc. R. Bot. Belg. 9, 157-321.

[2] Sachs, J. (1879) Ueber Ausschliessung der geotropischen und heliotropischen Krümmungen während des Wachsens. Arb. Bot. Inst. Würzbg. 2, 209-225.

[3] Massart, J. (1888) Recherches sur les organismes inférieurs 1. La loi de Weber vérifiée pour l'héliotropisme du champignon. Bull. Acad. R. Sci. Belg. 3 (Ser. 16), 590-601.

[4] Elfving, F. (1881) En obeaktad Känslighet hos Phycomyces. Bot. Not. 4, 105-107.

[5] Blakeslee, A.F. (1904) Sexual reproduction in the Mucorineae. Proc. Am. Acad. Arts Sci. 40, 205-319. 
[6] Tabernaemontanus (1588-1590) Neuw vollkommentlich Kreuterbuch. Frankfurt am Main.

[7] Blakeslee, A.F. (1906) Zygospore germinations in the Mucorineae. Ann. Mycol. 4, 1-28.

[8] Burgeff, H. (1912) Über Sexualität, Variabilität und Vererbung bei Phycomyces nitens. Ber. Dtsch. Bot. Ges. 30, 679-685.

[9] Burgeff, H. (1928) Variabilität, Vererbung und Mutation bei Phycomyces blakesleeanus Bgff. Z. Vererbungsl. 49, 26-94.

[10] Bergman, K., Eslava, A.P. and Cerdá-Olmedo, E. (1973) Mutants of Phycomyces with abnormal phototropism. Mol. Gen. Genet. 123, 116.

[11] Cerdá-Olmedo, E. and Lipson, E.D. (1987) Phycomyces. Cold Spring Harbor Laboratory Press, New York.

[12] Lipson, E.D. and Horwitz, B.A. (1991) Photosensory reception and transduction. In: Sensory Receptors and Signal Transduction (Spudich, J.L. and Satir, B.H., Eds.), pp. 1-64. Wiley-Liss, New York.

[13] Cerdá-Olmedo, E. and Martín-Rojas, V. (1996) Phototropism in Phycomyces. In: Light as an Energy Source and Information Carrier in Plant Physiology (Jennings, C., Zucchelli, G., Ghetti, F. and Colombetti, G., Eds.), pp. 293-299. Plenum Press, New York.

[14] Galland, P. (2001) Phototropism in Phycomyces. In: Photomovement (Häder, D.P. and Lebert, M., Eds.), Elsevier Science, 621-657.

[15] Cerdá-Olmedo, E. and Corrochano, L.M. (2001) Genetics of Phycomyces and its responses to light. In: Photomovement (Häder, D.P. and Lebert, M., Eds.), pp. 589-620. Elsevier Science.

[16] Corrochano, L.M. and Cerdá-Olmedo, E. (1992) Sex, light and carotenes: the development of Phycomyces. Trends Genet. 8, 268-274.

[17] Avalos, J., Bejarano, E.R. and Cerdá-Olmedo, E. (1993) Photoinduction of carotenoid biosynthesis. Methods Enzymol. 214, 283-294.

[18] Fukshansky, L. (1993) Intracellular processing of a spatially non-uniform stimulus: case study of phototropism in Phycomyces. J. Photochem. Photobiol. B Biol. 19, 161-186.

[19] Ortega, J.K.E. (1990) Governing equations for plant cell growth. Physiol. Plant 79, 116-121.

[20] Zalokar, M. (1969) Intracellular centrifugal separation of organelles in Phycomyces. J. Cell Biol. 41, 494-509.

[21] Mehta, B. and Cerdá-Olmedo, E. (2001) Intersexual partial diploids of Phycomyces. Genetics 158, 635-641.

[22] Roncero, M.I.G., Zabala, C. and Cerdá-Olmedo, E. (1984) Mutagenesis in multinucleate cells: the effects of $N$-methyl- $N^{\prime}$-nitro- $N$-nitrosoguanidine on Phycomyces spores. Mutat. Res. 125, 195-204.

[23] Heisenberg, M. and Cerdá-Olmedo, E. (1968) Segregation of heterokaryons in the asexual cycle of Phycomyces. Mol. Gen. Genet. 102, $187-195$.
[24] De la Guardia, M.D., Aragón, C.M.G., Murillo, F.J. and CerdáOlmedo, E. (1971) A carotenogenic enzyme aggregate in Phycomyces: evidence from quantitative complementation. Proc. Natl. Acad. Sci. USA 68, 2012-2015.

[25] Cerdá-Olmedo, E. and Reau, P. (1970) Genetic classification of the lethal effects of various agents on heterokaryotic spores of Phycomyces. Mutat. Res. 9, 369-384.

[26] Orejas, M., Peláez, M.I., Alvarez, M.I. and Eslava, A.P. (1987) A genetic map of Phycomyces blakesleeanus. Mol. Gen. Genet. 210, 6976.

[27] Cerdá-Olmedo, E. (1975) The genetics of Phycomyces blakesleeanus. Genet. Res. 25, 285-296.

[28] Heeswijck, R. and Roncero, M.I.G. (1984) High frequency transformation of Mucor with recombinant plasmid DNA. Carlsberg Res. Commun. 49, 691-702.

[29] Jesaitis, A.J. (1974) Linear dichroism and orientation of the Phycomyces photopigment. J. Gen. Physiol. 63, 1-21.

[30] Ootaki, T. and Tsuru, T. (1993) Diphasic negative phototropism of sporangiophores of the piloboloid mutant of Phycomyces blakesleeanus. Exp. Mycol. 17, 103-108.

[31] Flores, R., Dederichs, A., Cerdá-Olmedo, E. and Hertel, R. (1999) Flavin-binding sites in Phycomyces. Plant Biol. 1, 645-655.

[32] Arrach, N., Fernández-Martín, R., Cerdá-Olmedo, E. and Avalos, J. (2001) A single gene for lycopene cyclase, phytoene synthase and regulation of carotene biosynthesis in Phycomyces. Proc. Natl. Acad. Sci. USA 98, 1687-1692.

[33] Weinkove, D., Poyatos, J.A., Greiner, H., Oltra, E., Avalos, J., Fukshansky, L., Barrero, A.F. and Cerdá-Olmedo, E. (1998) Mutants of Phycomyces with decreased gallic acid content. Fungal Genet. Biol. 25, 196-203.

[34] Eibel, P., Schimek, C., Fries, V., Grolig, F., Schapat, T., Schmidt, W., Schneckenburger, H., Ootaki, T. and Galland, P. (2000) Statoliths in Phycomyces: Characterization of octahedral protein crystals. Fungal Genet. Biol. 29, 211-220.

[35] Page, R.M. (1962) Light and the asexual reproduction of Pilobolus. Science 138, 1238-1246.

[36] Cerdá-Olmedo, E. and Avalos, J. (1994) Oleaginous fungi: carotenerich oil from Phycomyces. Prog. Lipid. Res. 33, 185-192.

[37] Barrero, A.F., Oltra, J.E. and Poyatos, J.A. (1996) Acidic metabolites from Phycomyces blakesleeanus. Phytochemistry 2, 1427-1433.

[38] Fischer, E.P. and Lipson, C. (1988) Thinking About Science. Max Delbrück and the Origins of Molecular Biology. Norton, New York. 